This is the accepted version of the article:

García, B.; Saiz-Poseu, J.; Gras-Charles, R.; Hernando, J.; Alibés, R.; Novio, F.; Sedó, J.; Busqué, F.; Ruiz-Molina, D.. Mussel-inspired hydrophobic coatings for water-repellent textiles and oil removal. ACS Applied Materials and Interfaces, (2014). 6. 20: 17616 - . 10.1021/am503733d.

Available at: https://dx.doi.org/10.1021/am503733d 


\title{
Mussel-inspired hydrophobic coatings for water- repellent textiles and oil removal
}

\author{
Beatríz García, ${ }^{1}$ Javier Saiz-Poseu, ${ }^{2}$ Roser Gras-Charles, ${ }^{3}$ Jordi Hernando, ${ }^{3}$ Ramon Alibés ${ }^{3}$ \\ Fernando Novio, ${ }^{2,4}$ Josep Sedó, ${ }^{2,4} *$ Félix Busqué, ${ }^{3} *$ Daniel Ruiz-Molina ${ }^{2,4}$
}

${ }^{1}$ Fundació Privada Ascamm, Parc Tecnològic del Vallès, Av. Universitat Autònoma, 23 E-08290 Cerdanyola del Vallès (Spain).

${ }^{2}$ ICN2 - Institut Català de Nanociència i Nanotecnologia, Campus UAB, 08193 Bellaterra, (Spain).

${ }^{3}$ Departament de Química, Universitat Autònoma de Barcelona, Campus UAB, 08193 Bellaterra (Spain).

${ }^{4}$ CSIC - Consejo Superior de Investigaciones Científicas, ICN2 Building, Campus UAB, 08193 Bellaterra (Spain).

KEYWORDS: catechol, mussel inspired, coating, hydrophobic, textile, pollutant removal

ABSTRACT. A series of catechol derivatives with a different number of linear alkyl chain substituents, and different length, have been shown to polymerize in the presence of aqueous ammonia and air, yielding hydrophobic coatings that present the ability to provide robust and efficient water repellency on weaved textiles, including hydrophilic cotton. The polymerization strategy presented exemplifies an alternative route to established melanin- and polydopaminelike functional coatings, affording designs in which all catechol (adhesive) moieties support specific functional side chains for the maximization of the desired (hydrophobic) functionality. 
The coatings obtained proved effective in the transformation of polyester and cotton weaves, as well as filter paper, into re-usable water-repellent, oil-absorbent materials, capable of retaining roughly double their weight in model compounds (n-tetradecane and olive oil), as well as of separating water/oil mixtures by simple filtration.

\section{INTRODUCTION}

In the last decades biomaterials have inspired the design and development of novel functional materials to scientists working in a broad variety of research fields. ${ }^{1,2,3}$ One example of this fruitful approach has been the fabrication of new bio-inspired materials based on catechol structures. ${ }^{4,5}$ These aromatic molecules bearing two ortho hydroxyl groups are ubiquitous in nature, where they display an impressive diversity of functional roles. For instance, catecholic aminoacids are found in mussel byssus proteins, where their presence is essential to their critical adhesive function in wet environments. ${ }^{6}$ In addition, alkyl-substituted catechols have also been identified as the main constituents of natural saps precursors of the polymeric glossy lacquers ${ }^{7}$ used as naturally sourced protective coatings in Eastern Asia for centuries. ${ }^{8,9}$ In the past years, researchers have been actively working in the development of simplified synthetic counterparts that take advantage of the remarkable adhesive and coating character of catechol-based materials. ${ }^{4,5}$ This is the case of mussel-inspired catechol-based polymers, which have emerged as versatile materials acting as protective layers, ${ }^{10,11}$ water-resistant adhesives, ${ }^{12,13,14}$ and primers for functional ad-layers. ${ }^{15,16}$ Among all different potential applications, one of the most widely explored is that of catechol-based coatings for controlling the wettability of surfaces and interfaces. ${ }^{17}$ 
Different synthetic approaches have been used for the fabrication of catechol-based polymeric materials. One such strategy consists of grafting catechol moieties as adhesive side groups in polymeric backbones to obtain (multi)layered films. ${ }^{18,19,20,21,22,23}$ Inspired by the pioneering work of Messersmith et al., ${ }^{24,25}$ the most widespread methodology for the control of surface wettability has been the melanin-like oxidative polymerization of dopamine into a polydopamine (PDA) primer coating, followed by its functionalization with appropriate side chains. ${ }^{26,27,28,29,30,31,32}$ In PDA, catechols and quinones are assumed to play complementary roles: on the one hand, $o$ dihydroxyl groups in non-oxidized catechol moieties presumably confer adhesion to substrates; on the other hand, residual, highly electrophilic $o$-quinones act as reactive points for the covalent attachment of functional side chains. PDA has accordingly been used to surface-modify carbon nanotubes and carbon fibers for high-performance polymer composites, ${ }^{33,34}$ and foams and mesh for high separation efficiency of oil/water mixtures ${ }^{35,36}$ and bioalcohols. ${ }^{37}$ In addition, PDA has been used, combining biomimetic principles, to obtain superhydrophobic surfaces. ${ }^{38,39,40}$ Despite its versatility and simplicity, PDA modification relies on the existence of a sufficient amount of reactive groups in the primer coating, which cannot be accurately controlled and, because of PDA insolubility, restricted to in situ polymerization methodologies.

Recently, we have reported the development of an alternative, simpler approach to fabricate catechol-based materials. ${ }^{41}$ In this novel strategy, a single monomer bearing both a catechol ring and at least one desired functional side chain (i.e., designed to carry a maximum amount of functional groups) is first synthesized, and then polymerized by means of a simple and inexpensive procedure consisting of treatment with ammonia in aerobic conditions. As would be the case of melanin-like materials, polymerization also takes place by means of a complex mechanism involving oxidation of the catechol ring, introduction of a nitrogen atom by covalent 
binding to this moiety, and further oxidation/cross-linking of the catechol unit, which, once aminated, is rendered more prone to oxidation. Compared to PDA, the main differences would be, first, the nitrogen source -which is endogenous in the case of catecholamines, and external in our case (ammonia)-, and more importantly, the fact that this novel approach does not rely on uncontrolled residual reactivity in order to introduce a specific functionality in the coating, because it is already built in the catecholic monomer. Regardless of the functional moiety, the polymerization mechanism is thus unique and generalizable provided that it is tolerant of the reaction conditions (presence of ammonia, moderately basic $\mathrm{pH}$, and contact with air).

Preliminary results showed that this approach can be used to modify the surface tension of a representative variety of substrates, both at the nano- and macroscale, by quick and ex situ deposition of robust coatings and without any surface pretreatment. As a follow-up to this study, here we present the practical application of this new strategy to the optimization of a robust hydrophobic coating by choice of the side functional chain length, number of chains, and coating conditions of a series of 4-alkylcatechols (1-4). The catechol starting materials and the synthetic methodology followed are schematically showed in Figure 1. Remarkably, we found that all coatings tested were soluble in a few common organic solvents, thus side-stepping the need to coat surfaces by in-situ procedures: polymeric materials could be isolated first, and subsequently applied to different substrates by dissolving them in an appropriate medium and systematically evaluating the deposition conditions for optimal performance. 
a)

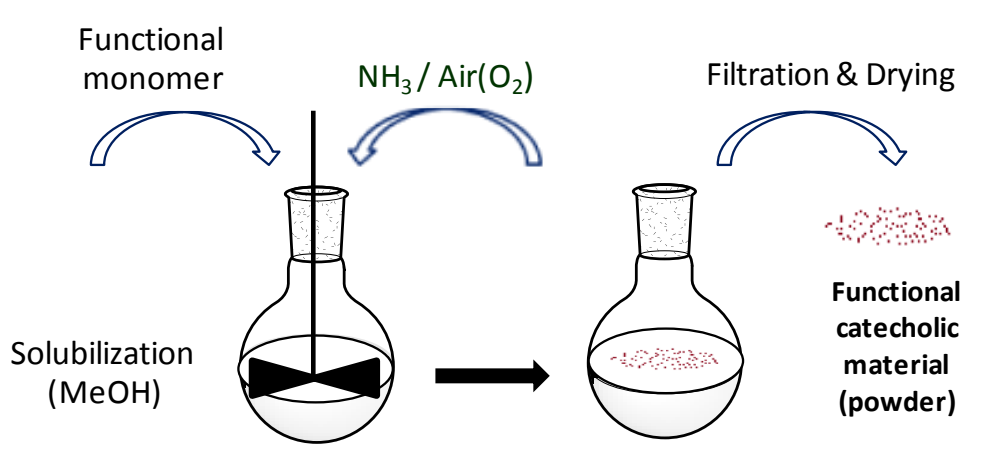

b)

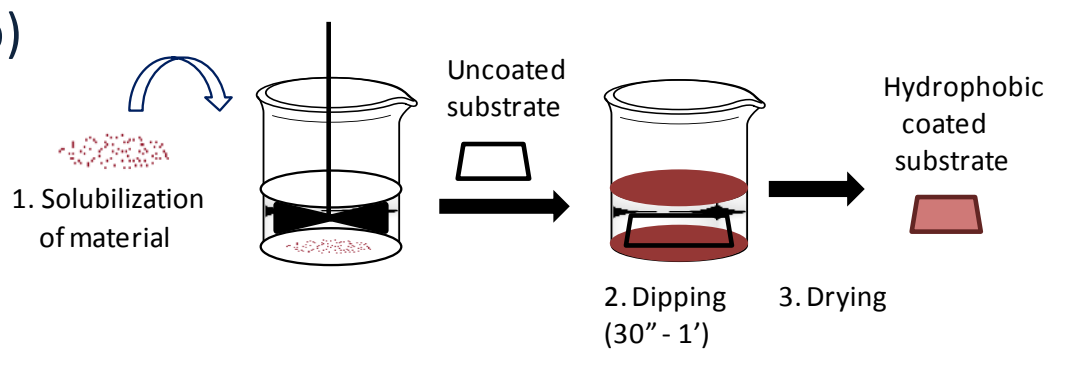<smiles>CC(C)(C)CCc1ccc(O)c(O)c1</smiles><smiles>CC(C)(C)CCc1ccc(O)c(O)c1</smiles>

Poly- $\mathrm{C}_{6}$ : M2

Poly-C 11 : M3<smiles>CC(C)(C)CCc1ccc(O)c(O)c1</smiles><smiles>CC(C)(C)CCCc1cc(CCC(C)(C)C)cc(O)c1O</smiles>

Poly- $C_{17}$ : M1

Poly- $\left(C_{17}\right)_{2}$ : M4

Figure 1. (a) Synthetic procedure for materials M1, M2, M3 and M4 from the corresponding catechols 1 (C17 alkyl chain), 2 (C6 alkyl chain), 3 (C11 alkyl chain), and 4 (2 C17 alkyl chains), respectively. (b) General coating procedure. 


\section{EXPERIMENTAL SECTION.}

Commercially available reagents were purchased from Sigma-Aldrich and used as received. Solvents were dried by distillation over appropriate drying agents. Chemical reactions involved in the synthesis of monomers were carried out under nitrogen, avoiding moisture by standard procedures, and were monitored by analytical thin layer chromatography (TLC) using silica gel F254 pre-coated Al plates ( $0.25 \mathrm{~mm}$ thickness). Silica gel 60 (particle size 35-70) was used for purification by flash column chromatography.

Chemical characterization. ${ }^{1} \mathrm{H}-\mathrm{NMR}$ spectra were recorded on a Bruker DP550 spectrometer (250 MHz, $\left.\mathrm{CDCl}_{3}, \delta=7.26 \mathrm{ppm}\right) .{ }^{13} \mathrm{C}-\mathrm{NMR}$ spectra were recorded on a Bruker DP550 spectrometer $\left(62.5 \mathrm{MHz} ; \mathrm{CDCl}_{3}, \delta=77.2 \mathrm{ppm} /\right.$ Acetone- $\left.\mathrm{d}_{6}, \delta=39.5 \mathrm{ppm}\right)$, with complete proton decoupling. Infrared spectra were recorded on a Sapphire-ATR Spectrophotometer. High resolution mass spectra (HRMS) were recorded with a Micromass-AutoSpec using (ESI+). X-ray photoelectron spectroscopy (XPS) analyses were conducted in order to identify the chemical states of the elements with a PHI 5550 Multisystem spectrometer with a monochromatic Al K $\alpha$ radiation $(1486.6 \mathrm{eV})$.

Contact Angle (CA). The CA of miliQ water droplets (ca. $5 \mu \mathrm{L}$ ) on coated substrates was used to evaluate the hydrophobicity of coated samples at room temperature by means of the sessile drop technique. An Easy Drop Standard analyzer and the Drop Shape Analysis DSA 10 software (Krüss, Hamburg) were used throughout. The reported values arise from averaging CA measurements on five different spots of each sample. 
Optical Microscopy. Optical microscopy images were obtained with an Axio Observer Z1m (Zeiss) inverted optical microscope, equipped with five different magnification lenses (5x,10x, 20x, 50x and 100x), and an XY motorized sample holder. The excitation source used was a short-arc high pressure Hg lamp (HBO 103/2, 100W).

Scanning Electron Microscopy. SEM measurements were carried out with a HITACHI S-570 and a QUANTA FEI 200 FEG-ESEM, both operating at $15 \mathrm{kV}$. Coated glass and textile substrates were fixed on SEM holders using adhesive carbon tape. Prior to observation with SEM, all samples were metalized with a thin layer of gold using a sputter coater K550 (Emitech).

Synthesis of $(Z)$ - and $(E)$ - 1,2-bis(methoxymethoxy)-4-(hex-1-enyl) benzene (6). Pentyltriphenylphosphonium bromide (10.69 g, $22.11 \mathrm{mmol})$ was dissolved in anhydrous THF (105 $\mathrm{mL})$ under nitrogen and $t$-BuOK $(4.29 \mathrm{~g}, 38.23 \mathrm{mmol})$ was added portion-wise. After stirring for $10 \mathrm{~min}$, a solution of $\mathbf{5}^{42}(4.55 \mathrm{~g}, 0.020 \mathrm{mmol})$ in anhydrous THF $(35 \mathrm{~mL})$ was added to the reaction mixture, which was stirred for $3 \mathrm{~h}$ at the reflux temperature. After cooling, the reaction was quenched with water $(80 \mathrm{~mL})$, the phases were separated and the aqueous layer was extracted with EtOAc $(3 \times 10 \mathrm{~mL})$. The combined organic phases were dried over $\mathrm{MgSO}_{4}$ and concentrated under reduced pressure to afford crude material which was purified by column chromatography (hexanes-EtOAc, 15:1) to give a mixture (10:1) of Z- and E- 6 (4.43 g, 15.80 mmol, $79 \%$ yield) as an oil. IR (ATR) v 3002, 2954, 2825, 1603, 1578, 1508, 1465, 1395, 1252, $1225,1201,1151,1126,1071,987,921,821 \mathrm{~cm}^{-1} ;{ }^{1} \mathrm{H}$ NMR $\left(250 \mathrm{MHz}, \mathrm{CDCl}_{3}\right) \delta 7.12(\mathrm{~d}, J=$ $2.4 \mathrm{~Hz}, 1 \mathrm{H}), 7.11(\mathrm{~d}, J=8.2 \mathrm{~Hz}, 1 \mathrm{H}), 6.89(\mathrm{dd}, J=8.4,2.2 \mathrm{~Hz}, 1 \mathrm{H}), 6.31(\mathrm{~d}, J=11.6 \mathrm{~Hz}, 1 \mathrm{H})$, $6.10(\mathrm{dt}, J=15.8,6.7 \mathrm{~Hz}, 1 \mathrm{H}-E), 5.60(\mathrm{dt}, J=11,6,7.3 \mathrm{~Hz}, 1 \mathrm{H}-\mathrm{Z}), 5.23(\mathrm{~s}, 4 \mathrm{H}), 3.52(\mathrm{~s}, 6 \mathrm{H})$, 
$2.33(\mathrm{~m}, 2 \mathrm{H}), 1.40(\mathrm{~m}, 4 \mathrm{H}), 0.90(\mathrm{t}, J=7.07 \mathrm{~Hz}, 3 \mathrm{H}) .{ }^{13} \mathrm{C} \mathrm{RMN}\left(62.5 \mathrm{MHz}, \mathrm{CDCl}_{3}\right) \delta 146.8$ $145.8,132.5,132.4,128.0,123.0,117.4,116.3,95.5,95.4,56.2,56.1,32.2,28.4,22.5,14.0$. HRMS (ESI+) calcd for $\mathrm{C}_{16} \mathrm{H}_{24} \mathrm{O}_{4} \mathrm{Na}[\mathrm{M}+\mathrm{Na}]^{+}$303.1567, found: 303.1564 .

Synthesis of 1,2-bis(methoxymethoxy)-4-hexylbenzene (7). To a stirred solution of a mixture of $Z$ - and $E$ - 6 (4.41 g, $15.76 \mathrm{mmol})$ in a mixture of $\mathrm{MeOH}(32 \mathrm{~mL})$ and THF $(63 \mathrm{~mL}), \mathrm{Pd} / \mathrm{C}$ $(418 \mathrm{mg})$ and ammonium formate $(3.20 \mathrm{~g}, 50.0 \mathrm{mmol})$ were added. The mixture was heated to reflux for $15 \mathrm{~h}$, allowed to cool down to room temperature, filtered through Celite and concentrated under reduced pressure to afford 7 (4.37 g, 99\% yield): IR (ATR) v 2926, 2854, $1588,1508,1378,1258,1226,1200,1151,1127,1071,989,922,812 \mathrm{~cm}^{-1} ;{ }^{1} \mathrm{H}$ NMR $(250 \mathrm{MHz}$, $\left.\mathrm{CDCl}_{3}\right) \delta 7.07(\mathrm{~d}, J=8.2 \mathrm{~Hz}, 1 \mathrm{H}), 7.00(\mathrm{~d}, J=1.9 \mathrm{~Hz}, 1 \mathrm{H}), 6.79(\mathrm{dd}, J=6.4,1.5 \mathrm{~Hz}, 4 \mathrm{H}), 5.24$ (s, 2H), $5.22(\mathrm{~s}, 2 \mathrm{H}), 3.55(\mathrm{~s}, 3 \mathrm{H}), 3.54(\mathrm{~s}, 3 \mathrm{H}), 2.55(\mathrm{t}, J=7.5 \mathrm{~Hz}, 2 \mathrm{H}) 1.61(\mathrm{~m}, 2 \mathrm{H}), 1.32(\mathrm{~m}$, $6 \mathrm{H}), 0.92(\mathrm{t}, J=6.6 \mathrm{~Hz}, 3 \mathrm{H}) ;{ }^{13} \mathrm{C} \mathrm{NMR}\left(62.5 \mathrm{MHz}, \mathrm{CDCl}_{3}\right) \delta$ 147.1, 145.1, 137.6, 122.2, 117.0, 116.8, 95.6, 95.5, 56.1, 56.1, 35.5, 31.7, 31.6, 29.0, 22.6, 14.1. HRMS (ESI+) calcd for $\mathrm{C}_{16} \mathrm{H}_{26} \mathrm{O}_{4} \mathrm{Na}[\mathrm{M}+\mathrm{Na}]^{+}$305.1723, found 305.1726.

Synthesis of 4-hexylcatechol (2). Compound 7 (4.46 g, 15.8 mmol) was disolved in $\mathrm{MeOH}$ (208 $\mathrm{mL}$ ) and $1.5 \mathrm{~mL}$ of concentrated $\mathrm{HCl}$ were added. The mixture was heated to reflux for $3 \mathrm{~h}$. Evaporation of the solvent under reduced pressure provided a solid residue which was dissolved in ethyl acetate $(10 \mathrm{~mL})$, and washed with a $\mathrm{NaHCO}_{3}$ saturated solution $(3 \times 30 \mathrm{~mL})$. The organic phase was dried over $\mathrm{MgSO}_{4}$ and concentrated under vacuum to afford $2(3.01 \mathrm{~g}, 15.5 \mathrm{mmol}$, $98 \%$ yield) as an oil: IR (ATR) v 3492, 3454, 3346, 2953, 2925, 2851, 1605, 1519, 1468, 1442, $1355,1331,1274,1254,1183,1114 \mathrm{~cm}^{-1} ;{ }^{1} \mathrm{H} \mathrm{NMR}\left(250 \mathrm{MHz}, \mathrm{CDCl}_{3}\right) \delta 6.75(\mathrm{~d}, J=8.0 \mathrm{~Hz}$, 1H), $6.68(\mathrm{~d}, J=1.9 \mathrm{~Hz}, 2 \mathrm{H}), 6.59(\mathrm{dd}, J=8.0,1.9 \mathrm{~Hz}, 1 \mathrm{H}), 2.47(\mathrm{t}, J=7.5 \mathrm{~Hz}, 2 \mathrm{H}), 1.53(\mathrm{~m}$, 2H), $1.28(\mathrm{~m}, 6 \mathrm{H}), 0.86(\mathrm{t}, J=6.5 \mathrm{~Hz}, 3 \mathrm{H}) ;{ }^{13} \mathrm{C} \mathrm{NMR}\left(62.5 \mathrm{MHz}, \mathrm{CDCl}_{3}\right) \delta 143.5,141.4,136.1$, 
120.7, 115.6, 115.3, 35.3, 31.8, 31.6, 29.0, 22.6, 14.1. HRMS (ESI-) calcd for $\mathrm{C}_{12} \mathrm{H}_{17} \mathrm{O}_{2}\left[\mathrm{M}-\mathrm{H}^{+}\right]^{-}$ 193.1234, found: 193.1232 .

Synthesis of $(Z)$ - and (E)- 1,2-bis(metoxymetoxy)-4-(undec-1-enyl) benzene (8). Decyltriphenylphosphonium bromide $(9.60 \mathrm{~g}, 19.86 \mathrm{mmol})$ was dissolved in anhydrous THF (110 mL) under nitrogen and $t$-BuOK $(4.23 \mathrm{~g}, 37.69 \mathrm{mmol})$ was added portion-wise. After stirring for 10 min, a solution of $\mathbf{5}(4.49 \mathrm{~g}, 19.85 \mathrm{mmol})$ in anhydrous THF $(30 \mathrm{~mL})$ was added to the reaction mixture, which was stirred for $3 \mathrm{~h}$ at the reflux temperature. After cooling, the reaction was quenched with water $(90 \mathrm{~mL})$, the phases were separated and the aqueous layer was extracted with EtOAc $(3 \times 30 \mathrm{~mL})$. The combined organic phases were dried over $\mathrm{MgSO}_{4}$ and concentrated under reduced pressure to afford crude material which was purified by column chromatography (hexanes-EtOAc, 10:1) to give a mixture (9:1) of $Z$ - and $E-8$ (5.32 g, $77 \%$ yield) as an oil: IR (ATR) v 2923, 2853, 1581, 1509, 1465, 1397, 1257, 1225, 1202, 1152, 1125 , $1072 \mathrm{~cm}^{-1} ;{ }^{1} \mathrm{H} \mathrm{NMR}\left(250 \mathrm{MHz}, \mathrm{CDCl}_{3}\right) \delta 7.14(\mathrm{~d}, J=2.5 \mathrm{~Hz}, 1 \mathrm{H}), 7.13(\mathrm{~d}, J=8.2 \mathrm{~Hz}, 1 \mathrm{H}), 6.92$ $(\mathrm{dd}, J=8.5,2.2 \mathrm{~Hz}, 1 \mathrm{H}), 6.34(\mathrm{~d}, J=11.6,6.7 \mathrm{~Hz}, 1 \mathrm{H}), 6.12\left(\mathrm{dt}, J=15.8,6.7 \mathrm{~Hz}, \mathrm{H}_{\mathrm{E}}\right), 5.62(\mathrm{dt}$, $\left.J=11.6,7.3 \mathrm{~Hz}, \mathrm{H}_{\mathrm{Z}}\right), 5.25(\mathrm{~s}, 4 \mathrm{H}), 3.55(\mathrm{~s}, 6 \mathrm{H}), 2.34(\mathrm{~m}, 2 \mathrm{H}), 1.30(\mathrm{~m}, 14 \mathrm{H}), 0.91(\mathrm{t}, J=6.6 \mathrm{~Hz}$ $4 \mathrm{H}) ;{ }^{13} \mathrm{C}$ NMR $\left(62.5 \mathrm{MHz}, \mathrm{CDCl}_{3}\right) \delta 146.79,145.78,132.53,128.01,122.98,117.36,116.24$, $95.52,95.41,56.16,56.12,31.91,30.02,29.60,29.57,29.45,29.33,29.25,22.70,14.13$. HRMS (ESI+) calcd for $\mathrm{C}_{21} \mathrm{H}_{34} \mathrm{O}_{4} \mathrm{Na}[\mathrm{M}+\mathrm{Na}]^{+}$373.2349, found 373.2349.

Synthesis of 1,2-bis(methoxymethoxy)-4-undecilbenzene (9). To a stirred solution of a mixture of $Z$ - and $E$ - 8 (5.32 g, $15.18 \mathrm{mmol})$ in EtOAc $(135 \mathrm{~mL}), \mathrm{Pd} / \mathrm{C}(610 \mathrm{mg})$ was added. The mixture was hydrogenated under a flow of $\mathrm{H}_{2}$ overnight. The mixture was filtered through Celite and concentrated under reduced pressure to afford 9 (5.07 g, $14.4 \mathrm{mmol}, 91 \%$ yield): IR (ATR) v 2923, 2853, 1589, 1509, 1465, 1398, 1259, 1225, 1201, 1152, 1128, $1072 \mathrm{~cm}^{-1} ;{ }^{1} \mathrm{H}$ NMR $(250$ 
$\left.\mathrm{MHz}, \mathrm{CDCl}_{3}\right) \delta 7.05(\mathrm{~d}, J=8.2 \mathrm{~Hz}, 1 \mathrm{H}), 6.97(\mathrm{~d}, J=2.0 \mathrm{~Hz}, 1 \mathrm{H}), 6.76(\mathrm{dd}, J=8.2,2.0 \mathrm{~Hz}, 1$ H), $5.22(\mathrm{~s}, 2 \mathrm{H}), 5.19(\mathrm{~s}, 2 \mathrm{H}), 3.52(\mathrm{~s}, 3 \mathrm{H}), 3.51(\mathrm{~s}, 3 \mathrm{H}), 1.58(\mathrm{t}, J=7.4 \mathrm{~Hz}, 2 \mathrm{H}), 2.53(\mathrm{~m}$, $2 \mathrm{H}), 1.30-1.23(\mathrm{~m}, 16 \mathrm{H}), 0.88(\mathrm{t}, J=6.6 \mathrm{~Hz}, 3 \mathrm{H}) ;{ }^{13} \mathrm{C} \mathrm{NMR}\left(62.5 \mathrm{MHz}, \mathrm{CDCl}_{3}\right) \delta 147.15$, $145.16,137.62,122.16,116.99,116.83,95.66,95.50,56.13,56.06,35.49,31.92,31.62,29.68$, 29.64, 29.63, 29.53, 29.35, 29.25, 22.75, 14.17. HRMS (ESI+) calcd for $\left[\mathrm{C}_{21} \mathrm{H}_{36} \mathrm{O}_{4} \mathrm{Na}\right][\mathrm{M}+\mathrm{Na}]^{+}$ 375.2506, found: 375.2509 .

Synthesis of 4-undecylcatechol (3). Compound 9 (3.78 g, $10.7 \mathrm{mmol})$ was dissolved in $\mathrm{MeOH}$ $(175 \mathrm{~mL})$ and $1.4 \mathrm{~mL}$ of concentrated $\mathrm{HCl}$ were added. The mixture was heated to reflux for $3 \mathrm{~h}$. Evaporation of the solvent under reduced pressure provided a solid residue which was dissolved in diethyl ether $(75 \mathrm{~mL})$, and washed with a $\mathrm{NaHCO}_{3}$ saturated solution $(3 \times 30 \mathrm{~mL})$. The organic phase was dried over $\mathrm{MgSO}_{4}$ and concentrated under vacuum to afford 3 (2.75 g, $10.4 \mathrm{mmol}$, 97\% yield) as an oil: IR (ATR) v 3451, 3339, 2952, 2915, 2850, 1601, 1520, 1472, 1357, 1336, 1278, 1184, 1146, 1117, $1091 \mathrm{~cm}^{-1} ;{ }^{1} \mathrm{H}$ NMR $\left(250 \mathrm{MHz}, \mathrm{CDCl}_{3}\right) \delta 6.79(\mathrm{~d} . J=8.0 \mathrm{~Hz}, 1 \mathrm{H}), 6.73$ (d, $J=1.9 \mathrm{~Hz}, 1 \mathrm{H}), 6.63(\mathrm{dd}, J=8.0,2.0 \mathrm{~Hz}, 1 \mathrm{H}), 2.51(\mathrm{t}, J=7.2 \mathrm{~Hz}, 2 \mathrm{H}), 1.29(\mathrm{~m}, 16 \mathrm{H}), 0.90(\mathrm{t}$, $J=6.6 \mathrm{~Hz}, 3 \mathrm{H}) ;{ }^{13} \mathrm{C} \mathrm{NMR}\left(62.5 \mathrm{MHz}, \mathrm{CDCl}_{3}\right) \delta 143.25,141.14,136.35,120.81,115.50,115.21$, 35.25, 31.93, 31.62, 29.68, 29.64, 29.61, 29.53, 29.35, 29.25, 22.71, 14.10. HRMS (ESI-) calcd for $\left[\mathrm{C}_{17} \mathrm{H}_{28} \mathrm{O}_{2}\right]\left[\mathrm{M}-\mathrm{H}^{+}\right]^{-}$263.2017, found: 263.2013.

\section{Synthesis of polymers. General procedure:}

A solution of catechol $(0.5 \mathrm{~g})$ in $50 \mathrm{~mL}$ of methanol $(1 \% \mathrm{w} / \mathrm{v})$ was heated to $40{ }^{\circ} \mathrm{C}$ and a 100 molar excess of ammonia (25\% aqueous solution) was added drop-wise over 5 min. After stirring for $24 \mathrm{~h}$ at $40{ }^{\circ} \mathrm{C}$, the dark solution was diluted with $60 \mathrm{~mL}$ of water and the excess of ammonia and methanol were removed under reduced pressure. The resulting aqueous solution was treated with concentrated $\mathrm{HCl}$ until the $\mathrm{pH}$ was slightly acid and extracted with hexane $(3 \mathrm{x}$ 
$80 \mathrm{~mL}$ ). The combined organic phases were dried over $\mathrm{MgSO}_{4}$ and concentrated under reduced pressure to afford a slightly brown solid material which was used without further purification.

\section{RESULTS AND DISCUSSION}

3.1. Synthetic route for functional catechol precursors. The synthesis and characterization of long-chain 4-heptadecylcatechol (1) and 3,5-diheptadecylcatechol (4) have been already reported elsewhere. ${ }^{43,44}$ Short and medium chain-length alkyl-catechols $\mathbf{2}$ and $\mathbf{3}$ were obtained by means of an analogous synthetic route, depicted in Scheme 1. Briefly, the hydroxyl groups of commercial 3,4-dihydroxybenzaldehyde were protected as the corresponding methoxymethyl ethers, yielding aldehyde 5. At this point, synthetic pathways diverged towards target compounds 2 and 3 . The Wittig reaction of aldehyde $\mathbf{5}$ with pentyltriphenylphosphonium bromide and potassium tert-butoxide in dry THF afforded olefin 6 in $79 \%$ yield as a 10:1 mixture of $Z$ - and $E$ - isomers, which was hydrogenated using ammonium formate under palladium catalysis to afford 7 in almost quantitative yield. Finally, cleavage of the methoxymethyl ethers in refluxing methanol with acidic catalysis provided the target 4hexylcatechol 2 in quantitative yield. An analogous set of reactions starting from aldehyde 5, but using decyltriphenylphosphonium bromide as the phosphorane precursor, led to the synthesis of 4-undecylcatechol 3. Overall yields from the starting aldehyde were $71 \%$ and $63 \%$ for 2 and $\mathbf{3}$, respectively. 


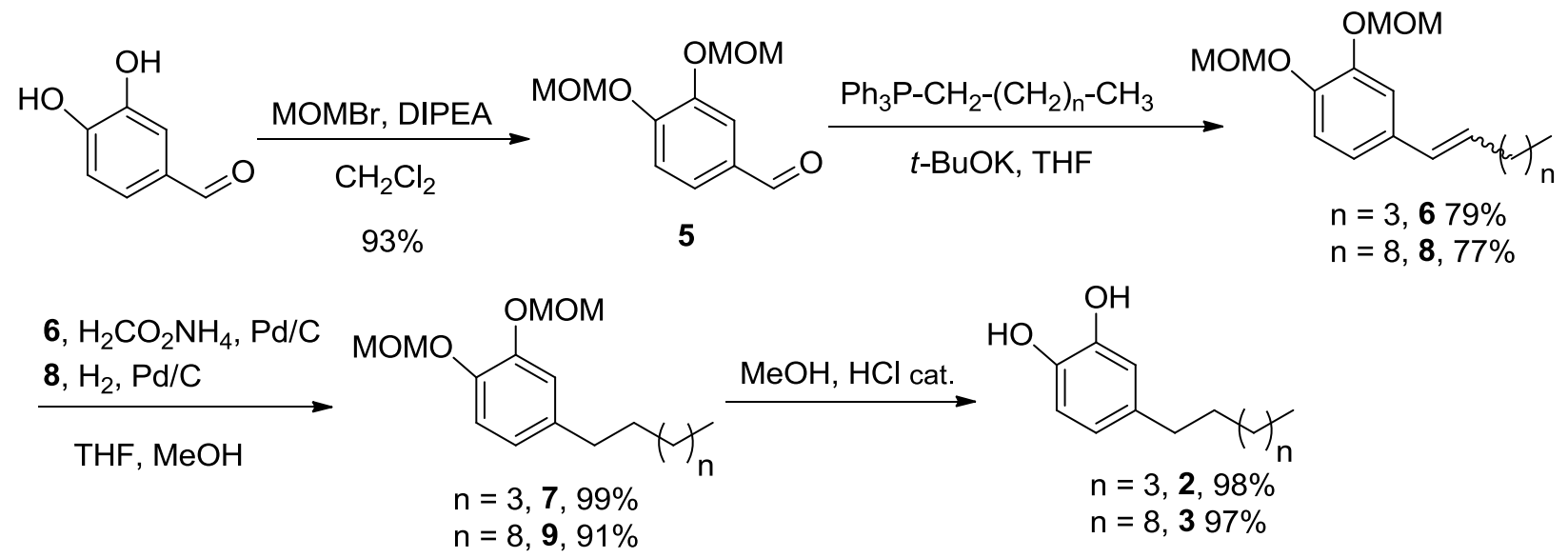

Scheme 1. Synthesis of target catechols $\mathbf{2}$ and $\mathbf{3}$

3.2. Preparation and characterization of catechol-based polymeric materials. The new polymeric catechol derivatives, M2, M3 and M4, derived respectively from precursors 2, 3 and 4, were prepared following a previously reported protocol for the preparation of ammoniapolymerized 4-heptadecylcatechol (M1) with an $85 \%$ yield. ${ }^{41}$ In all cases, the reaction was essentially quantitative within a few hours, as evinced by the formation of turbid dark-brown dispersions and the disappearance of the starting monomeric catechol. In order to isolate the polymeric materials, the reaction mixture was diluted with water, methanol and ammonia were removed under reduced pressure, and the aqueous suspension was acidified to $\mathrm{pH} 5$ and extracted with $n$-hexane. M1, M2, M3 and M4 were obtained by evaporation from dry $n$-hexane phases as dark brown solids, and characterized by NMR and IR (Supporting Information Figures S1 and S2). As previously reported for M1 $1{ }^{41}{ }^{1} \mathrm{H}-\mathrm{NMR}$ spectra of the new polymeric materials M2, M3 and M4 only exhibit clear signals corresponding to part of the aliphatic nuclei of the alkyl chains, with only very broad, weak and unstructured features in other areas of the 
${ }^{1} \mathrm{H}-\mathrm{NMR}$ spectrum. This observation is consistent with the hypothesis that isolated materials are likely mixtures of oligomers under strong dynamic effects at room temperature. The presence of significant amounts of free radicals in the polymeric materials as a possible explanation for this anomaly was already ruled out in a previous study of $\mathbf{M 1} \mathbf{1}^{41}$ by electron paramagnetic resonance (EPR) and SQUID magnetization measurements.

IR spectra of M2 and M3 show distinctive peak profiles, in which two new signals not present for the starting catechol monomers stand out; namely, a medium peak around $1676 \mathrm{~cm}^{-1}$, which could be assigned to carbonyl groups in $o$-quinone moieties, and a strong peak near $1575 \mathrm{~cm}^{-1}$, which could be attributed to electronically poor olefins, although in both cases peaks might be also assigned to imine bonds arising from Schiff-base condensations between ammonia/amines and o-quinone carbonyl groups. Based on these and previously reported data on polymer M1, a plausible pathway for the polymerization reaction would start with the oxidation of the parent catechol by aerobic oxygen in basic media to the corresponding $o$-quinone, followed by 1,2- or 1,4-addition of ammonia to form either a Schiff base or a Michael-type adduct, respectively (see supporting information for details). The simultaneous occurrence of any of these reactions, and subsequent tautomerization processes and reactions between all these intermediates in different oxidation states would lead to highly disordered oligomeric systems presenting both $o$-quinone and catechol moieties. Overall, the difficulties encountered in the elucidation of the molecular structures of isolated materials are not surprising but reminiscent to those encountered in previous and ongoing research on other catechol polymeric compounds obtained by melanization, such as natural and synthetic eumelanins ${ }^{45}$ and polydopamine. ${ }^{46,47}$

3.3. Coating properties. In stark contraposition to natural and synthetic melanins ${ }^{45}$ and polydopamine, ${ }^{46,47}$ which are essentially insoluble in common organic solvents, all materials 
herein described (M1, M2, M3, M4) were soluble in certain common organic solvents, such as $n$-hexane or chloroform. This allowed us to use a simple ex-situ methodology for its application as coatings on different surfaces without any prior priming or pre-treatment of the woven surfaces. In a typical experiment, a $25 \mathrm{~cm}^{2}$ sample of the surface to be coated was immersed for 1 minute in a $0.1-1 \%(\mathrm{w} / \mathrm{v})$ solution of the polymeric material in chloroform, rinsed with clean solvent and dried. The hydrophobicity of the coated samples was characterized by contact angle measurements with water drops (Table 1).

We studied first the effect of alkyl side-chain length on the performance of the resulting hydrophobic coatings. Glass slides treated with solutions of materials M2 and M3 showed very similar CA values -around $80^{\circ}$-, regardless of the length of the linear alkyl chain present in the starting catechols ( 66 and $\mathrm{C} 11$, respectively), but slightly below that of $\mathbf{M 1}\left(88^{\circ}\right),{ }^{41}$ derived from long-chain (C17) catechol 1. Polyester fabric coated with M2 and M3 showed similar CA values -around $130^{\circ}-$, close to that reported for M1 $\left(134^{\circ}\right)$. These CAs are substantially higher than those measured on glass surfaces, and fully consistent with the general observation that surface roughness exacerbates the intrinsic hydrophobicity of ideally flat substrates. ${ }^{48}$ Remarkably, coating layers applied in this fashion are still thin enough so as not to smear the textile with a continuous layer; i.e., coated fibers remain instead fully detached from each other, an essential precondition to preserve the breathability, flexibility and touch of the original textile material (Figure 2).

\begin{tabular}{|c|c|c|c|c|}
\hline Material & $\begin{array}{c}\text { Functional } \\
\text { substitution } \\
\text { pattern }\end{array}$ & Glass & Polyester & Cotton \\
\hline M1 & $4-C_{17}$ & $88.3 \pm 4.8$ & $134.1 \pm 8.1$ & $133.8 \pm 5.3$ \\
\hline
\end{tabular}




\begin{tabular}{|c|c|c|c|c|}
\hline M2 & $4-\mathrm{C}_{6}$ & $79.2 \pm 6.2$ & $129.7 \pm 7.8$ & 0 \\
\hline M3 & $4-\mathrm{C}_{11}$ & $81.1 \pm 5.7$ & $128.2 \pm 6.4$ & 0 \\
\hline M4 & $4,5-\mathrm{bis}\left(\mathrm{C}_{17}\right)$ & $102.3^{\mathrm{a}} \pm 6.3$ & $135.3 \pm 7.2$ & $129.3 \pm 6.7$ \\
\hline
\end{tabular}

${ }^{\text {a }} n$-hexane used as solvent

Table 1. Contact angle values obtained with water droplets on different substrates after treatment for 1' with a $1 \%(\mathrm{w} / \mathrm{v})$ chloroform solution of polymeric material.

\begin{tabular}{|l|c|c|}
\hline Uncoated & Polyester & Cotton \\
\hline M2-coated & & \\
\hline M3-coated & & \\
\hline
\end{tabular}




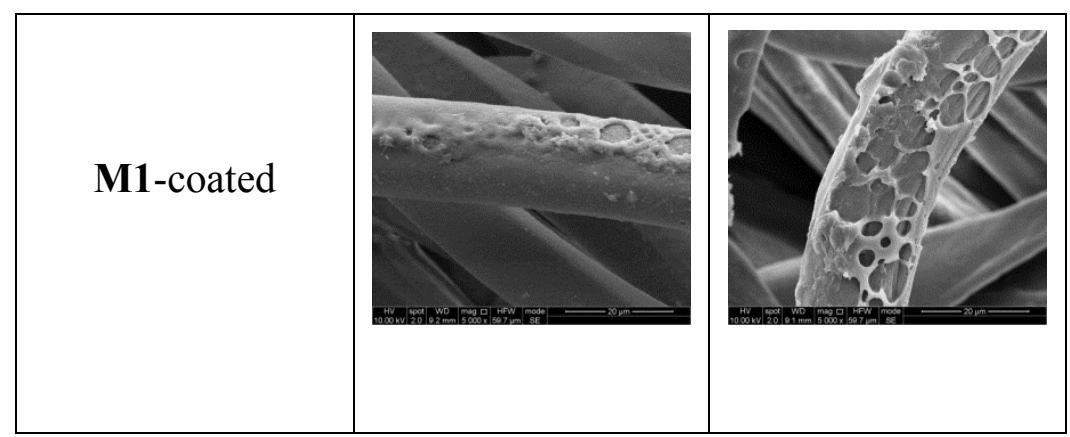

Figure 2. SEM images of uncoated and coated cotton and polyester weave. Coatings were prepared from $1 \%$ solutions of the respective polymers in $n$-hexane. The presence of a thin coating layer is evinced by edges and other layer irregularities, absent in images of the uncoated fibers.

In order to rank the efficacy of the coating materials, we measured CAs on coated polyester prepared from solutions of M1 (C17), M2 (C6) and M3 (C11) in different concentrations (0.1\%, $0.5 \%$ and $1 \%$ ) $\mathrm{w} / \mathrm{v}$ in chloroform (Figure $3 \mathrm{a}$ ). Here, the effect of alkyl chain length is very clear, since dilute solutions are unable to efficiently coat the polyester textile in the experimental conditions, as evinced by the fact that for $\mathbf{M} 2$ and $\mathbf{M 3}$ at $0.1 \% \mathrm{w} / \mathrm{v}$, water droplets were rapidly absorbed by the textile. At $0.5 \% \mathrm{w} / \mathrm{v}, \mathrm{M} 2$-bearing the shortest alkyl chain- yields contact angles around $30^{\circ}$ below the plateau value. On the other hand, even dilute solutions of M1 afforded near-optimal CAs. In order to qualitatively assess the robustness of optimal hydrophobic coatings, water droplets on top of a horizontal M1-coated piece of woven polyester were monitored for $10^{\prime}$ after vertical placement on the substrate. The hydrophobic layer was able to effectively hold the droplet, preventing both loss of CA and change of shape. Indeed, no collapse of the droplet or significant wetting of the fabric was observed throughout, with the droplet losing about $30 \%$ of its volume by evaporation (Figure $3 \mathrm{~b}$ ). 
a)

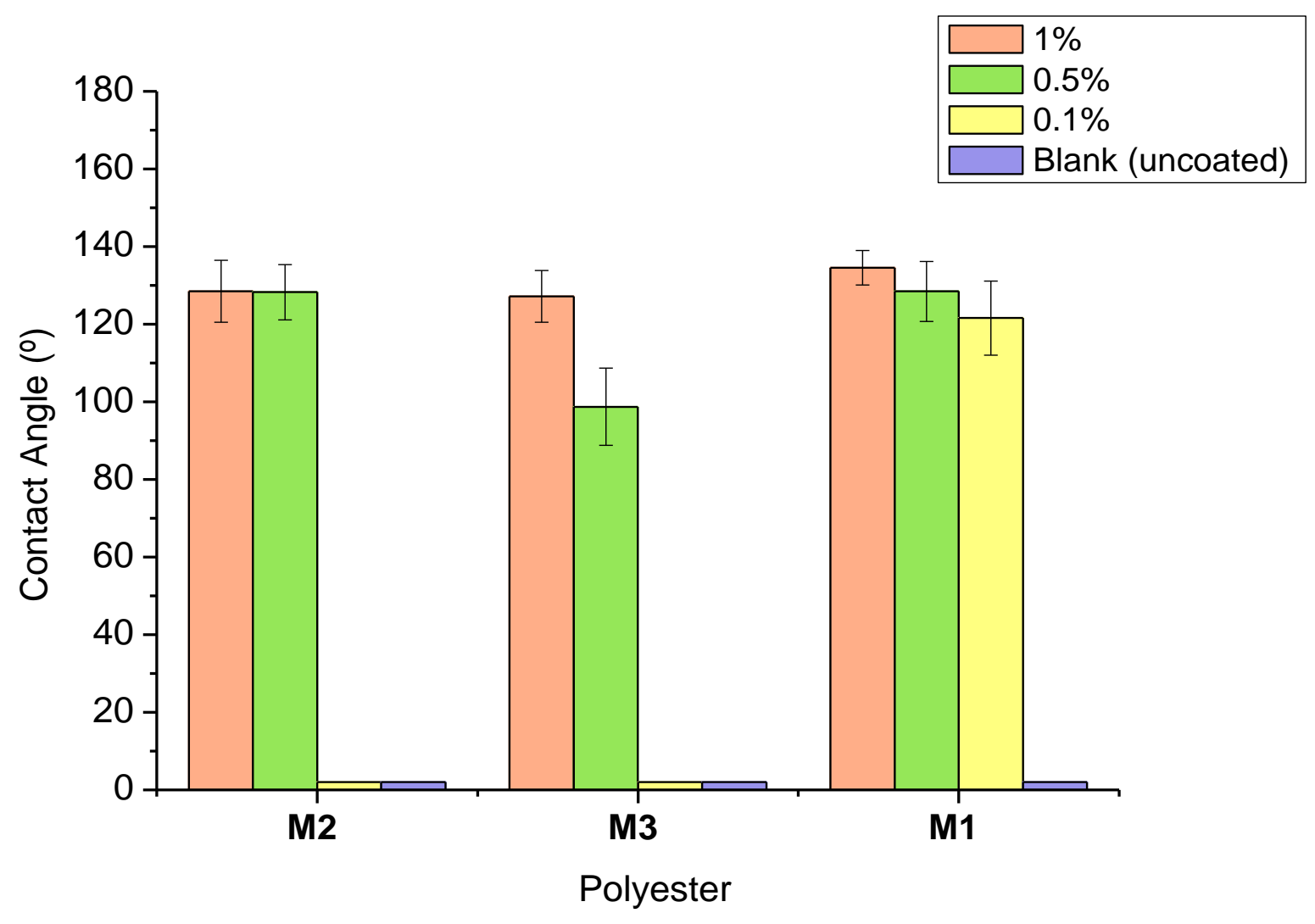

b)
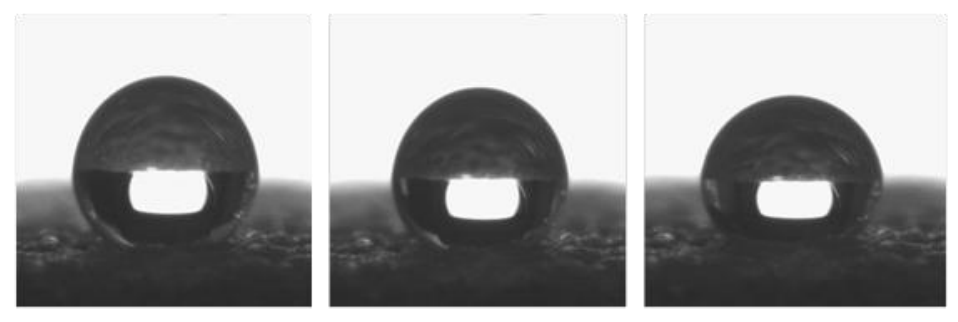

c) 


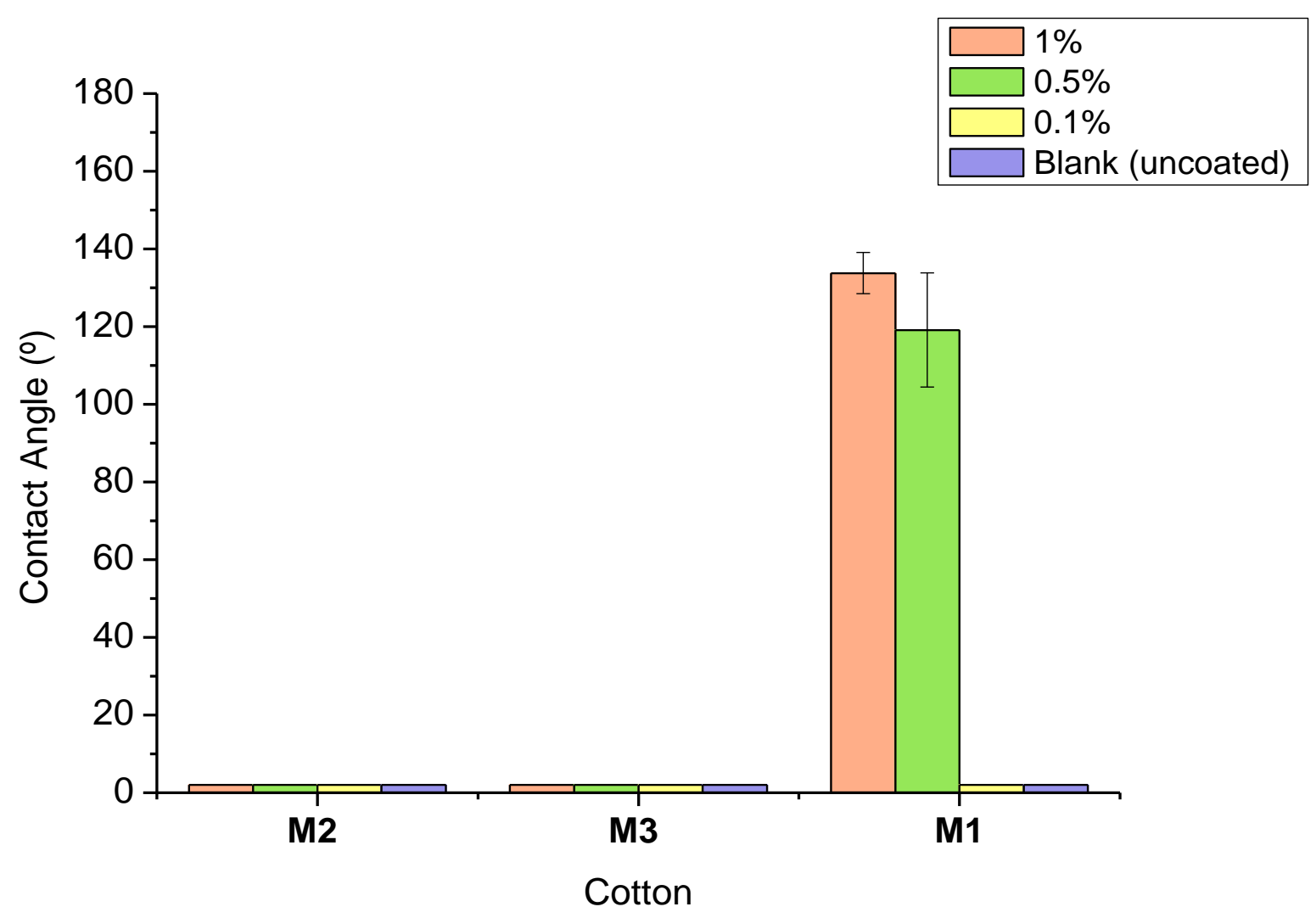

d)
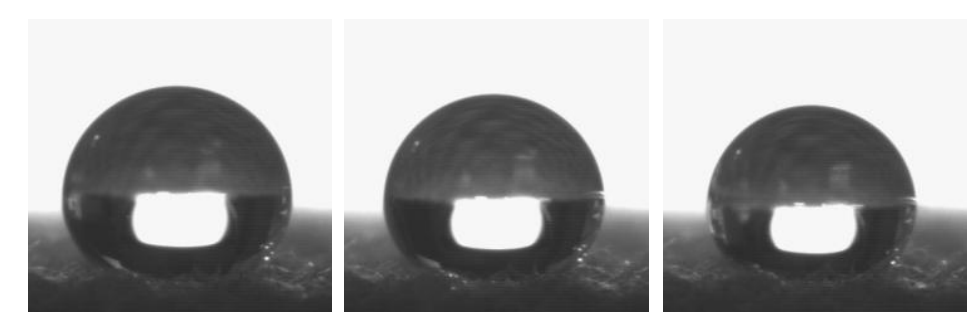

Figure 3. (a) Effect of solution concentration used for dip-coating on the efficacy of coating materials M2, M3 and M1 on polyester (a) and cotton (c). Zero values for CA indicate fast collapse $(<10 \mathrm{~s})$ of the water droplet due to absorption in the textile. Robustness of M1 coatings 
on polyester (b) and cotton (d) prepared from in 1\% w/v chloroform solutions: evolution of water droplets after 1', 5' and 10' (left to right).

The performance of these materials on real substrates was further tested on the cotton weave of a lab coat, which due to its high intrinsic hydrophilicity, surface area and absorption capability provided a more stringent test for the hydrophobization capacity of catechol-based polymers than polyester. In this case, the effect of alkyl chain length was more evident, since neither M2 (C6) nor M3 (C11) were able to provide water-repellency ( $\left.>1^{\prime}\right)$ that would last enough for us to take meaningful CA measurements. As far as M1 is concerned, very dilute coating solutions $(0.1 \%)$ were not effective, but even a $0.5 \% \mathrm{w} / \mathrm{v}$ solution already afforded reasonably good CA values, around $120^{\circ}$ (Figure 3c). For optimal coatings prepared from $1 \% \mathrm{w} / \mathrm{v}$ solutions, CA values consistently reached above $140^{\circ}$, thanks to weave roughness. Finally, M1 coatings on cotton passed as well the robustness test by keeping the fabric dry for at least 10', with no apparent loss on the CA value. As observed for polyester-coated surfaces, the absence of noticeable absorption in the fabric would indicate that the observed volume loss is due to slow evaporation of the liquid (Figure 3d).

In order to assess the effect of the double alkyl chain substitution, comparative CA measurements were taken on substrates coated with M4 - derived from catechol $\mathbf{4}$ and bearing two $\mathrm{C} 17$ substituents. On glass, M4 showed a moderate $15 \%$ higher $\mathrm{CA}\left(102^{\circ}\right)$ than those of polymers derived from single-substituted monomers (M1, M2 and M3). On a polyester textile coated according to the ex situ immersion procedure mentioned above, M4 afforded a CA value of $135^{\circ}$, essentially identical to that of M1, indicating that this is probably the maximum 
(optimal) CA angle achievable with this family of catechol-based hydrophobic coatings on the polyester fabric used. SEM images of M4-coated polyester fibers are similar to those already shown for the other materials, where the presence of a coating layer is clearly observed (see Supporting Information - Figure S3). On cotton, nevertheless, slightly lower CA values were recorded for $\mathbf{M 4}$, probably hinting at a lower polymerization degree, leading to a lesser robustness of this coating. In view of the comparative results of M1 and M4 and the performance of single-functionalized M1 on cotton, it seems clear that double long alkyl chain substitution on these catechol-based materials does not provide a significant improvement on their hydrophobic performance, whereas chain lengths of at least $\mathrm{C} 17$ proved critical in order to achieve satisfactory water-repellency.

To complete the characterization of coating properties, a series of experiments were carried out to assess the resistance of polymer M1 against chemical aging conditions. Firstly, we tested the in situ resistance of cotton samples (ca. $2 \mathrm{~cm} \times 2 \mathrm{~cm}$ ) previously coated from $1 \% \mathrm{w} / \mathrm{v}$ solutions of M1 in chloroform, as outlined above. For this, triplicate samples were subsequently kept at room temperature in aqueous $\mathrm{HCl} 1 \mathrm{M}, \mathrm{NaOH} 1 \mathrm{M}$ and 3\% w/v hydrogen peroxide, respectively, during $24 \mathrm{~h}$ with magnetic stirring. Test samples were then rinsed with $3 \times 100 \mathrm{~mL}$ of distilled water and dried at room temperature. After their respective treatments, samples aged in either aqueous acidic or oxidizing media afforded CAs statistically indistinguishable from those of unaged blanks, whereas those aged in basic conditions showed rapid absorption of water droplets (Figure 4a).

It should be noted that in the latter case the cut edges of the cotton weave were visibly ragged after the experiment, as opposed to the other aged samples, which showed no visible wear. We thus ran a second round of experiments in order to study the intrinsic resistance of the polymeric 
material, i.e., chemically aged prior to coating. In this case, aliquots of $100 \mathrm{mg}$ of polymer M1, as obtained from the synthetic procedure outlined previously, were directly suspended in $30 \mathrm{~mL}$ of aqueous $\mathrm{HCl} 1 \mathrm{M}, \mathrm{NaOH} 1 \mathrm{M}$, and 3\% w/v hydrogen peroxide, respectively, during 24 hours with magnetic stirring. Each suspension was then extracted with $2 \times 20 \mathrm{~mL}$ of $\mathrm{CHCl}_{3}$ and washed with 2 × $20 \mathrm{~mL}$ of water, after which $90 \mathrm{mg}$ of dry, aged polymer were isolated from the organic phase and dissolved in $9 \mathrm{~mL}$ of chloroform in order to coat cotton samples according to the above-mentioned procedure.

a)

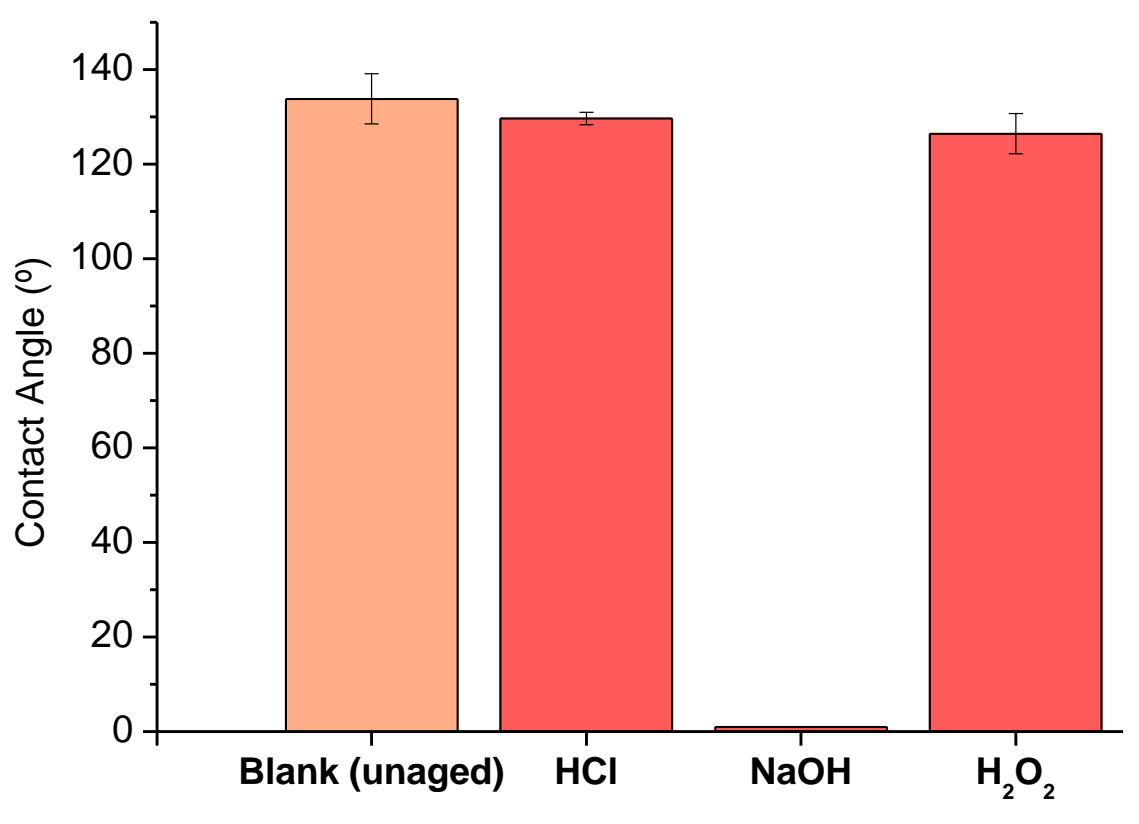

b) 


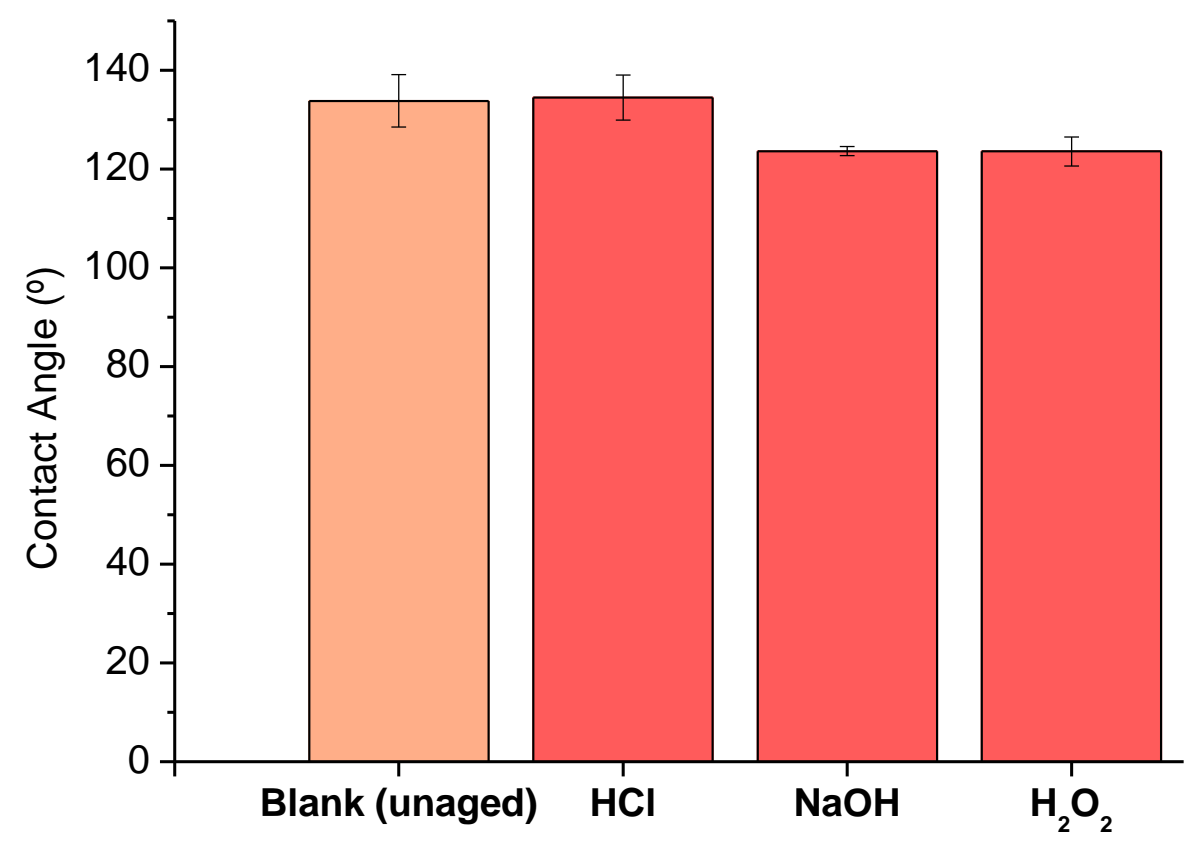

Figure 4. Chemical resistance of $\mathbf{M 1}$ coatings on cotton against acidic $(\mathrm{HCl} 1 \mathrm{M})$, basic $(\mathrm{NaOH}$ $1 \mathrm{M})$ and oxidizing $\left(\mathrm{H}_{2} \mathrm{O}_{2} 3 \% \mathrm{w} / \mathrm{v}\right)$ aqueous media: a) hydrophobicity of samples coated with $\mathbf{M 1}$ and subsequently treated in the aging media; b) hydrophobicity of samples coated with previously aged polymer M1.

In all cases, CA values of water droplets measured on samples coated with aged polymer were essentially identical to those of blank samples, i.e., coated with un-aged polymer (Figure 4b). Although it cannot be fully discarded that a very small amount of polymer had been solubilized in the aqueous phase as a result of any of the aging treatments, and subsequently resisted 
extraction in the organic phase, we conclude that the polymer did not suffer significant degradation in any of the tested media/conditions. In view of these results, the complete loss of hydrophobicity of coated cotton samples after aging in aqueous $\mathrm{NaOH} 1 \mathrm{M}$ is more likely attributable to physical degradation of the textile weave.

3.4. Oil absorption and phase separation tests. Because of its superior water-repellency performance, M1 was used as coating material for the assessment of the surface-modifying properties of this family of catechol-based coatings by means of oil-absorbance tests, as well as two simple oil/water separation experiments simulating the removal of oily pollutants from aqueous phases. In addition to cotton and polyester textiles as common-use materials, filter paper was also studied as a fibrous, absorbent non-textile model substrate.

Oil absorption capacities of treated absorbents. At first glance, the three materials show notable differences in morphology that are expected to determine their respective liquid absorption capacities (Supporting Information - Figure S4). Both cotton and polyester are woven materials made of bundles of single fibers with diameters of ca. $20 \mu \mathrm{m}$, but cotton's weave is thicker and less porous than that of polyester, which exhibits a relatively regular pore system. As opposed to textiles, filter paper appears as an unstructured material, where cellulose fibers are randomly oriented and loosely entangled/bound.

Due to their absorbent nature and medium to high polarity, all three untreated substrates are inherently capable of retaining varying amounts of oil, as well as water. Indeed, all three uncoated materials are stained by both oil and water droplets placed on their surface even in very short times (1-3s), as expected. In these regard, thus, untreated substrates act as undiscriminating 
absorbents. On the other hand, all treated substrates showed intrinsic water repellency (i.e. no water absorption) - as evinced by their buoyancy in water-, alongside significantly enhanced oil absorption. As far as net capacity $(c)$ is concerned, ${ }^{49}$ comparative tests were carried out using $n$ tetradecane (TDC) and pure olive oil as non-volatile model pollutants. For this purpose, coated samples of known dry weight were soaked in test oils for 10', taken out, allowed to drain for 30', and re-weighted. Compared to untreated substrates, oil absorption capacities roughly doubled in all cases, showing values between $100 \%$ and $180 \%(\mathrm{w} / \mathrm{w})$, depending on both the material and the oil phase tested (Table 2).

\begin{tabular}{|c|c|c|c|}
\hline \multirow{2}{*}{$\begin{array}{c}\text { Absorbent } \\
\text { Substrate }\end{array}$} & \multirow{2}{*}{ Water } & TDC & Oil \\
\cline { 3 - 4 } & & $\begin{array}{c}|c| \\
\text { Repellent } \\
(85 \% \pm 9)\end{array}$ & $\begin{array}{c}146 \% \pm 7 \\
(67 \% \pm 5)\end{array}$ \\
\hline \multirow{2}{*}{ Cotton } & Repellent & $101 \% \pm 9$ & $164 \% \pm 6$ \\
& $(92 \% \pm 9)$ & $(46 \% \pm 4)$ & $179 \% \pm 7$ \\
\hline \multirow{2}{*}{ Polyester } & Repellent & $86 \% \pm 3$ & $(89 \% \pm 7)$ \\
\hline \multirow{2}{*}{ Filter Paper } & $(140 \% \pm 13)$ & $(50 \% \pm 7)$ & $97 \% \pm 5$ \\
& & & $(61 \% \pm 3)$ \\
\hline
\end{tabular}

Table 2. Percentual weight absorption capacities of M1-coated and uncoated (in parentheses) absorbent substrates for liquid tests.

Although differences in absorption capacities between substrates may be largely attributed to significant variations in parameters such as porosity, surface area and regularity of the 
microstructure of the absorbents,${ }^{50}$ as well as the viscosity/smearing ability of the oil test liquids, these results demonstrate that the surface properties of household absorbent materials with differing morphologies can be very effectively tampered with the ex situ procedures described. This allows their intrinsic absorbent qualities to be turned around, without recourse to specific micro-patterning designs or chemical modification. Interestingly, the oil absorbent capacity of treated cotton vs $n$-tetradecane (146\%) turned out to be similar to that of the same substrate vs olive oil (164\%), and strikingly superior to the native water absorbent capacity of the untreated weave $(85 \%)$. This is quite remarkable, since $n$-tetradecane has a low viscosity $(2-3 \mathrm{cP})-$ comparable to that of water $(1 \mathrm{cP})-$, and does not appreciably smear treated substrates, in contrast to olive oil (viscosity ca. $80 \mathrm{cP}$; see Figure 5 for differential smearing effects).

\begin{tabular}{|c|c|c|c|}
\hline Coated substrate/ & Polyester & Cotton & Filter paper \\
Absorbant & & & \\
\hline (Dry) & & & \\
\hline & & & \\
\hline
\end{tabular}




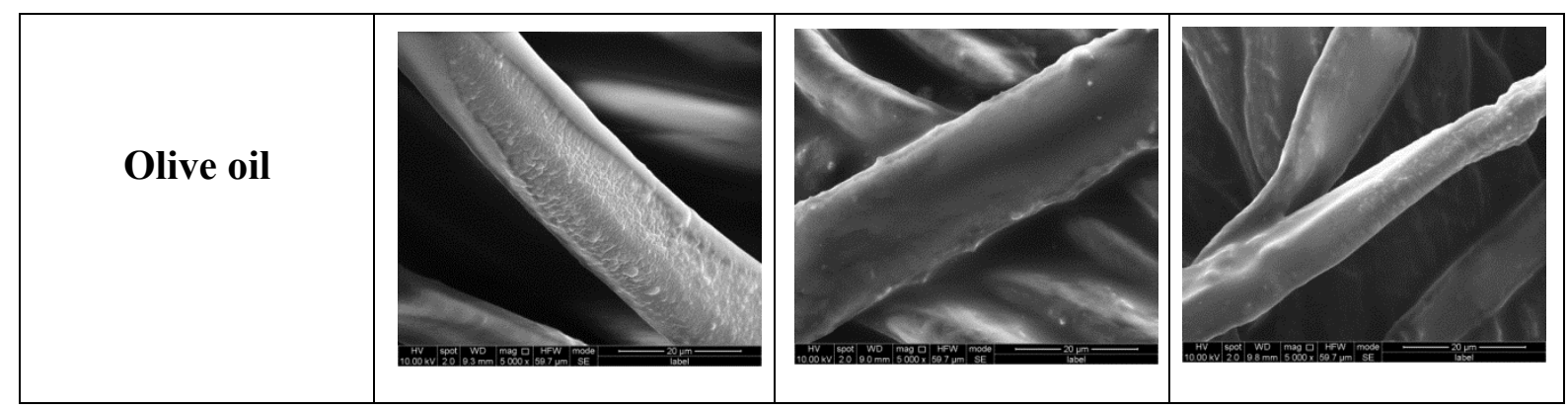

Figure 5. From left to right, SEM images of polyester, cotton and filter paper fibers after absorption of $n$-tetradecane (top) and olive oil (bottom). After draining of excess oil, no obvious smearing is observed for $n$-tetradecane; as opposed to olive oil.

The robustness of the hydrophobic coatings was further assessed by repeated cleaning and re-use cycles. The absorbed oil could be completely removed by rinsing oil-soaked substrates in an organic solvent such as ethanol or acetone, taken out, and then dried. Clean, treated substrates were then subject to five consecutive absorption/removal experiments, after which net adsorption capacities did not deteriorate, nor did substrate dry weights after re-use deviate significantly from their respective weights before use (Figure 6). CAs of the re-used coated materials after 5 cycles were shown to be comparable to their corresponding initial values (Supporting Information Table S1). 


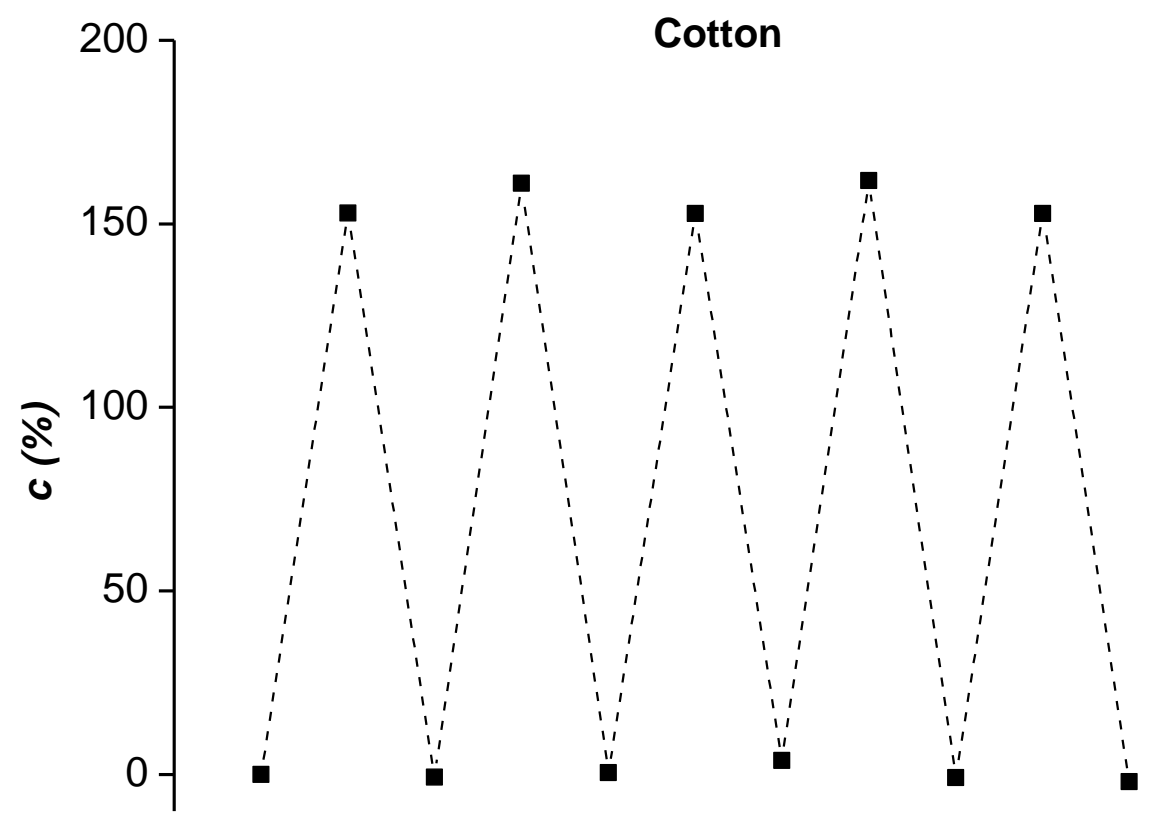



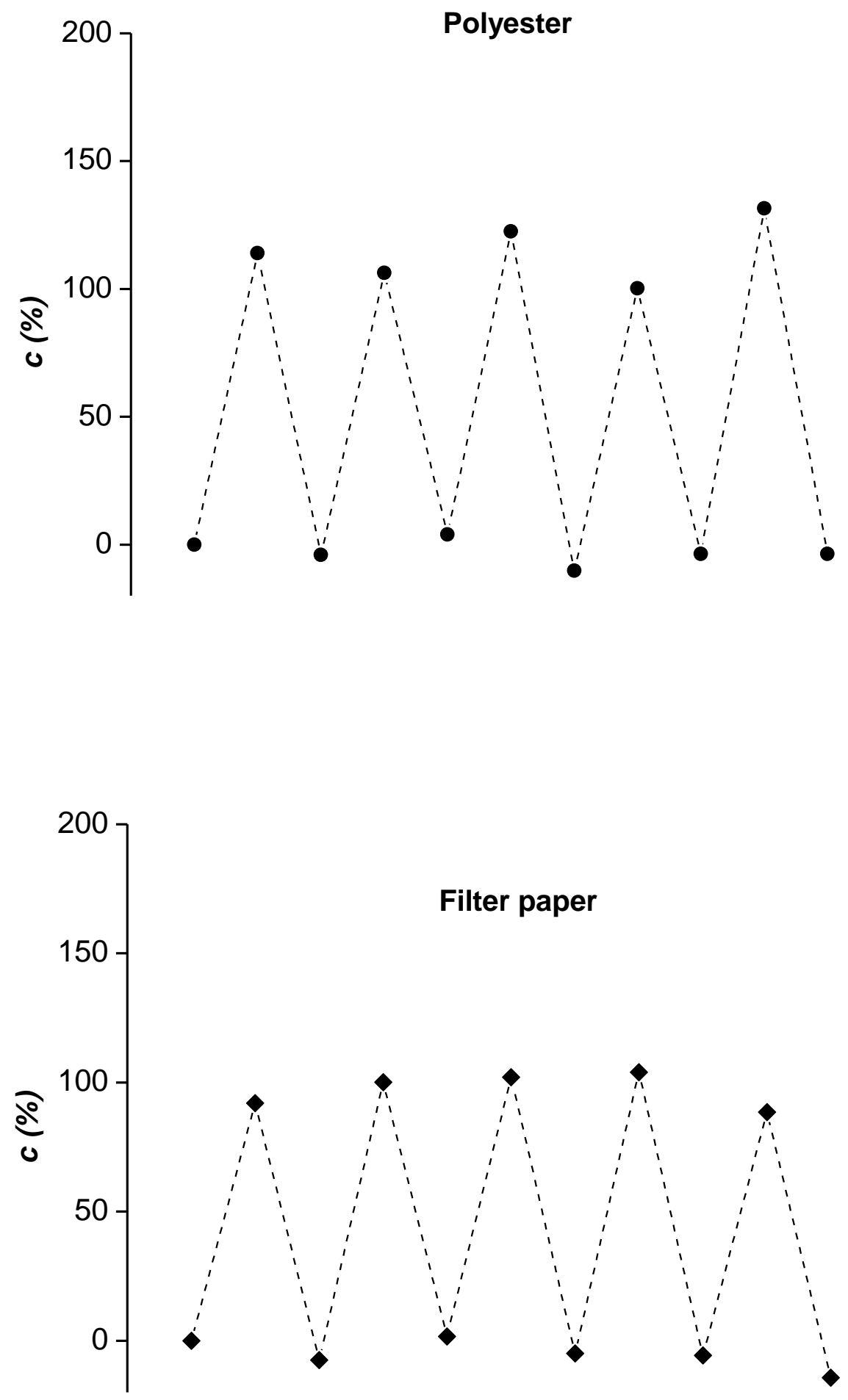
Figure 6. Recyclability of M1-coated fibrous substrates (cotton, polyester, filter paper) assessed by net oil absorption capacity, c. $5 n$-tetradecane absorption/cleaning cycles were carried out (immersion, 10'; draining, 30'; rinsing in ethanol, 30'). Clean substrates were dried under vacuum at $30^{\circ} \mathrm{C}$ for $1 \mathrm{~h}$ before re-weighting.

Removal of oil contaminants from water. Absorption capacity values determined for M1-coated substrates were used to simulate oil pollutant removal using these materials. With this aim, a ca. $2.5 \times 2.5 \mathrm{~cm}^{2}$ coated sample of known weight of a given substrate was put in contact for $10-15 \mathrm{~s}$ with a water/oil bath containing a quantity of oil equal to the corresponding saturation value of the substrate. The sample was then taken out of the mixture and weighted using the same protocol described above (Figure 7a-e) after excess oil drained. In these conditions, ca. 90-95\% of the initial oil weight could be removed by absorption onto the coated substrate. As above, an appropriate solvent could be used to rinse the oil from the absorbent material, which could then be further re-used.

Finally, the water-repellence of M1-coated cotton weaves was used for phase separation by filtration of a water/oil mixture. Because of the lipophilic and absorbent nature of treated surfaces, oils quickly soaked them and, after oil saturation, permeated through, while water was kept retained on top (Figure $7 \mathrm{f}$ ). 


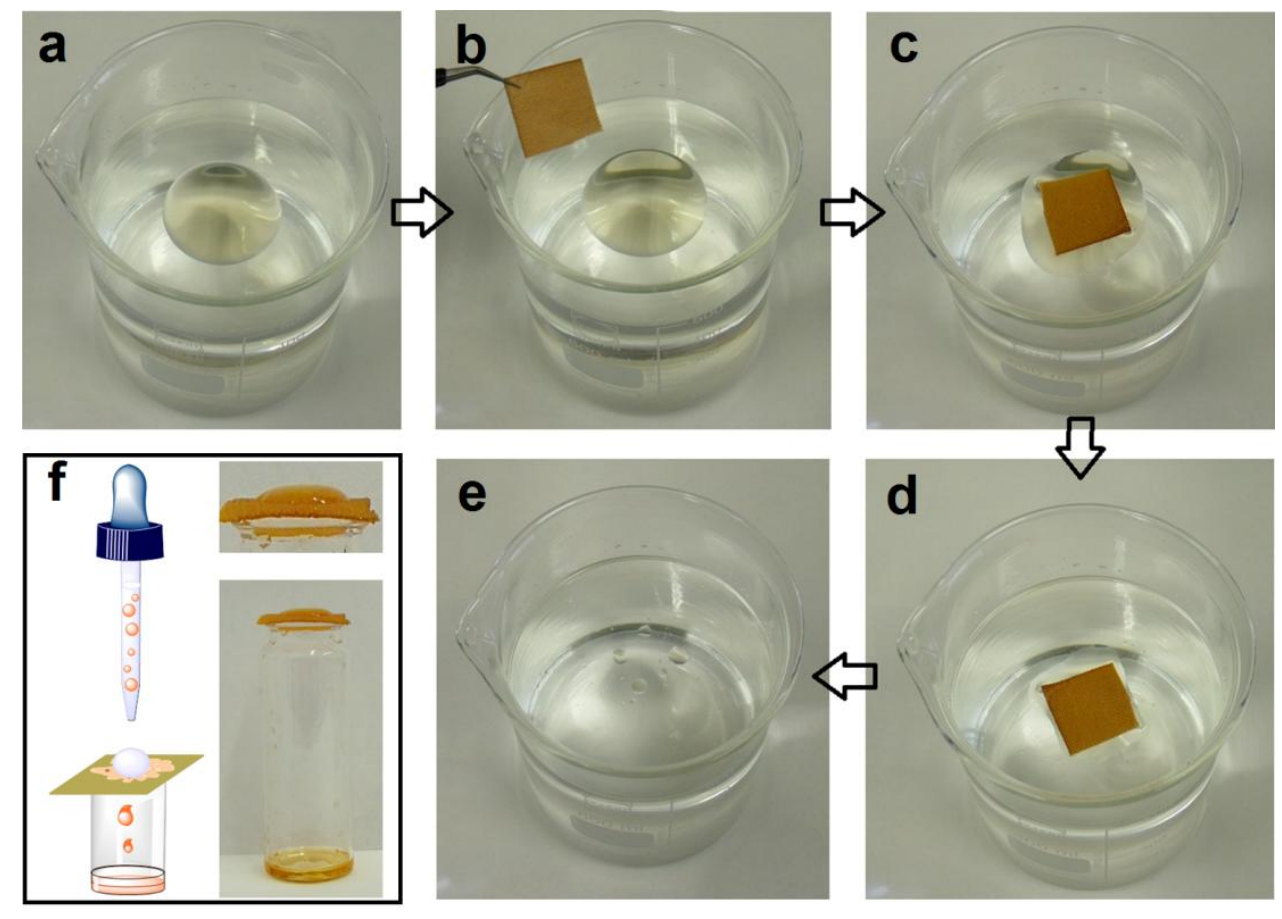

Figure 7: Selective oil removal: (a) n-tetradecane/water mixture; (b)-(e) oil is removed by soaking a M1-coated cotton sample. (f) Schematic representation of an oil/water phase separation by filtration over a hydrophobically coated substrate fiber (right); picture after filtration using a M1-coated cotton sample; water-phase retained on top (left). A small amount of dye was added to the oil phase to help with the visualization of the oil/water interface.

\section{CONCLUSIONS}

In summary, a new general strategy for the synthesis of functional catechols has been applied to the preparation and systematic study of the performance of a family of robust hydrophobic coatings. These compounds were obtained by polymerization of catechol derivatives differing in length and number of alkylic side-chains, by means of an oxidative mechanism reminiscent of 
that reported for polydopamine and eumelanin, but advantageous in two counts. Firstly, since the oxidative polymerization reaction makes use of an already functionalized catechol and an exogenous source of nitrogen (ammonia) in the presence of air, it affords functional polydopamine-like materials bearing a maximized-by-design content of the functional sidechain. Secondly, and in contrast to eumelanin, polydopamine and their Michael-addition reaction derivatives, these materials proved to be soluble in certain common organic solvents and thus amenable to very fast, simple ex situ treatments, which may be conveniently optimized in terms of coating conditions and are capable of affording ultrathin coatings on different substrates.

As a proof-of-concept of the viability of this procedure and the robustness of the water-repellent character of the polymeric materials, contact angles of coated samples of polyester and cotton weave were measured and their evolution with time was followed. Long alkyl chains of at least C17 were necessary in both cases to ensure effective water repellency, as attested by CA measurements. On the other hand, double substitution on the monomer proved redundant with regard to water repellency, in comparison with the $\mathrm{C} 17$ mono-substituted catechol derivative. As far as the optimal coating conditions are concerned, the most effective coatings were prepared by immersion of substrates for 1 ' in $0.5-1 \%$ chloroform solutions; higher concentrations or immersion times were not necessary to prepare fully effective water-repellent coatings even on highly hydrophilic cotton, showing no noticeable wetting or even loss of contact angle for at least $10^{\prime}$. These coatings showed effectiveness in the transformation of water-absorbent polyester and cotton weaves, as well as filter paper, into re-usable water-repellent, oil-absorbent substrates, capable of retaining roughly twice their weight of model hydrophobic compounds ( $n$-tetradecane and olive oil), as well as of separating water/oil mixtures by simple filtration. 


\section{Corresponding Author/s}

Dr. Josep Sedó, E-mail: jsedo@cin2.es. Dr. Félix Busqué, E-mail: Felix.Busque@uab.es.

\section{Acknowledgments.}

This work was partially funded by MICINN through projects MAT2012-38318-C03-02, MAT2012-38319-C02-01, CTQ2012-30853 and CTQ2010-15380, and a FPI predoctoral grant for R.G.-C. We are also grateful to Generalitat de Catalunya for project 2010VALOR00039 and a FI predoctoral grant for J. S.-P.

\section{Supporting Information Available.}

Further details on the chemical characterization of the polymeric materials prepared and the morphological and functional properties of the resulting coatings may be found in the Supporting Information file. This material is available free of charge via the Internet at http://pubs.acs.org. 


\section{TOC Graphic}

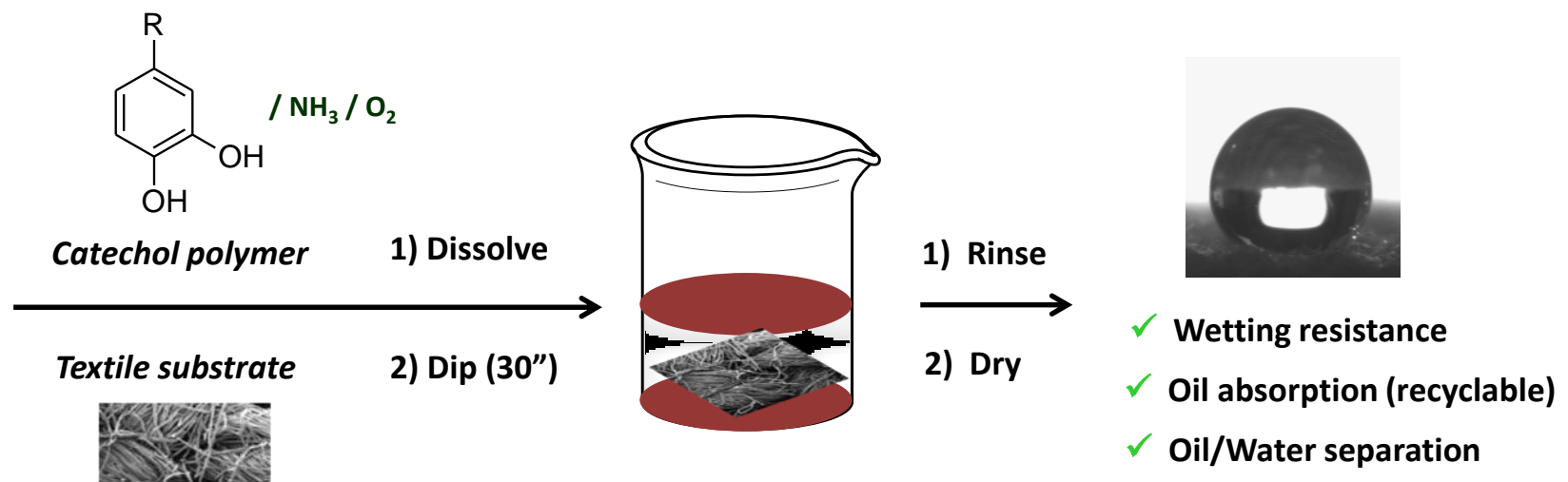




\section{References}

${ }^{1}$ Liu, K.; Jiang, L. Bio-inspired design of multiscale structures for function integration. Nano Today 2011, 6, 155-175.

${ }^{2}$ Xia, F.; Jiang, L. Bio-Inspired, Smart, Multiscale Interfacial Materials. Adv. Mater. 2008, 20, 2842-2858.

${ }^{3}$ Dujardin, E.; Mann, S. Bio-inspired Materials Chemistry. Adv. Mater. 2002, 14, 775-788.

${ }^{4}$ Sedó, J.; Saiz-Poseu, J.; Busqué, F.; Ruiz-Molina, D. Catechol-Based Biomimetic Functional Materials. Adv. Mater. 2013, 25, 653-701.

5 Yanlan, L.; Kelong, A.; Lehui, L. Polydopamine and its Derivative Materials: Synthesis and Promising Applications in Energy, Environmental, and Biomedical Fields. Chem. Rev. 2014, $114,5057-5115$.

6 Papov, V. V.; Diamond, T. V.; Biemann, K.; Waite, J. H. Hydroxyarginine-Containing Polyphenolic Proteins in the Adhesive Plaques of the Marine Mussel Mytilus edulis. J. Biol. Chem. 1995, 270, 20183-20192.

${ }^{7}$ Xia, J.; Xu, Y.; Lin, J. UV-Induced Polymerization of Urushiol. II: Effects of Hydrogenation Degree of Urushiol on Surface Morphology. Prog. Org. Coat. 2010, 67, 365-369.

8 Kumanotani, J. Enzyme Catalyzed Durable and Authentic Oriental Lacquer: a Natural Microgel-Printable Coating by Polysaccharide-Glycoprotein-Phenolic Lipid Complexes. Prog. Org. Coat. 1998, 34, 135-146.

${ }^{9}$ Lu, R.; Kamiya, Y.; Miyakoshi, T. Applied Analysis of Lacquer Films Based on Pyrolysis-Gas Chromatography/Mass Spectrometry. Talanta 2006, 70, 370-376.

${ }^{10}$ Dalsin, J. L.; Hu, B.-H.; Lee, B. P.; Messersmith, P. B. Mussel Adhesive Protein Mimetic Polymers for the Preparation of Nonfouling Surfaces. J. Am. Chem. Soc. 2003, 125, 4253-4258.

${ }^{11}$ Saxer, S.; Portmann, C.; Tosatti, S.; Gademann, K.; Zürcher, S.; Textor, M. Surface Assembly of Catechol-Functionalized Poly(L-lysine)-graft-poly(ethylene glycol) Copolymer on Titanium Exploiting Combined Electrostatically Driven Self-Organization and Biomimetic Strong Adhesion. Macromolecules 2010, 43, 1050-1060.

12 Lee, B. P.; Chao, C.-Y.; Nunalee, F. N.; Motan, E.; Shull, K. R.;. Messersmith, P. B. Rapid Gel Formation and Adhesion in Photocurable and Biodegradable Block Copolymers with High DOPA Content. Macromolecules 2006, 39, 1740-1748. 
${ }^{13}$ Lee, H.; Lee, B. P.; Messersmith, P. B. A Reversible Wet/Dry Adhesive Inspired by Mussels and Geckos. Nature 2007, 448, 338-342.

${ }^{14}$ Lee, Y.; Cheng, H. J.; Yeo, S.; Ahn, C.-H.; Lee, H.; Messersmith, P. B.; Park, T. G. Thermosensitive, Injectable, and Tissue Adhesive Sol-Gel Transition Hyaluronic Acid/Pluronic Composite Hydrogels Prepared from Bio-Inspired Catechol-Thiol Reaction. Soft Matter 2010, 6, 977-983.

15 Lee, H.; Dellatore, S. M.; Miller, W. M.; Messersmith, P. B. Mussel-Inspired Surface Chemistry for Multifunctional Coatings. Science 2007, 318, 426-430.

${ }^{16}$ Lee, H.; Rho, J.; Messersmith, P. B. Facile Conjugation of Biomolecules onto Surfaces Via Mussel Adhesive Protein Inspired Coatings. Adv. Mater. 2009, 21, 431-434.

${ }^{17}$ Webb, H. K.; Crawford, R. J.; Ivanova, E. P.; Wettability of Natural Superhydrophobic Surfaces Adv. Colloid Interface Sci. 2014, 210, 58-64.

${ }^{18}$ Neto, A. I.; Cibrão, A. C.; Correia, Cl. R.; Carvalho, R. R.; Luz, G. M.; Ferrer, G. G.; Botelho, G.; Picart, C.; Alves, N. M.; Mano J. F. Nanostructured Polymeric Coatings Based on Chitosan and Dopamine-Modified Hyaluronic Acid for Biomedical Applications. Small 2014, 10, 24592469.

19 Faure, E.; Falentin-Daudré, C.; Jérôme, Ch.; Lyskawa, J.; Fournier, D.; Woisel, P.; Detrembleur, Ch. Catechols as Versatile Platforms in Polymer Chemistry. Prog. Polym. Sci. 2013, 38, 236-270.

${ }^{20}$ Wu, J.; Zhang, L.; Wang, Y.; Long, Y.; Gao, H.; Zhang, X.; Zhao, N.; Cai, Y.; Xu, J. MusselInspired Chemistry for Robust and Surface-Modifiable Multilayer Films. Langmuir 2011, 27, 13684-13691.

${ }^{21}$ Wang, X.; Ye, Q.; Gao, T.; Liu, J.; Zhou, F. Self-Assembly of Catecholic Macroinitiator on Various Substrates and Surface-Initiated Polymerization. Langmuir 2012, 28, 2574-2581.

${ }^{22}$ Gong, Y.-K.; Liu, L.-P.; Messersmith, P. B. Doubly Biomimetic Catecholic Phosphorylcholine Copolymer. A Platform Strategy for Fabricating Antifouling Surfaces. Macromol. Biosci. 2012, $12,979-985$.

23 Kim, J. S.; Kim, T. G.; Kong, W. H.; Park, T. G.; Nam, Y. S. Thermally Controlled Wettability of a Nanoporous Membrane Grafted with Catechol-Tethered Poly(Nisopropylacrylamide). Chem. Commun. 2012, 48, 9227- 9229. 
24 Lee, H.; Dellatore, Sh. M.; Miller, W. M.; Messersmith, P. B. Mussel-inspired Surface Chemistry for Multifunctional Coatings. Science 2007, 318, 426-430.

${ }^{25}$ Dreyer, D. R.; Miller, D. J.; Freeman, B. D.; Paul, D. R.; Bielawski, C. W. Perspectives on Poly(dopamine). Chem. Sci. 2013, 4, 3796-3802.

${ }^{26}$ Jo, S.; Kang, S. M.; Park, S. A.; Kim, W. D.; Kwak, J.; Lee, H. Enhanced Adhesion of Preosteoblasts inside 3D PCL Scaffolds by Polydopamine Coating and Mineralization. Macromol. Biosci. 2013, 13, 1389-1395.

27 Shi, X.; Ostrovidov, S.; Shu, Y.; Liang, X.; Nakajima, K.; Wu, H.; Khademhosseini A. Microfluidic Generation of Polydopamine Gradients on Hydrophobic Surfaces. Langmuir 2014, $30,832-838$.

${ }^{28}$ Hong, D.; You, I.; Lee, H.; Lee, S.-G.; Choi, I. S.; Kang S. M. Polydopamine Circle-Patterns on a Superhydrophobic AAO Surface: Water-Capturing Property. Bull. Korean Chem. Soc. 2013, $34,3141-3142$.

29 Zheng, X.; Weng, J.; Li, S.; Liu, H.; Hu, B.; Li, Y.; Meng, X.; Ruan, H. Anticorrosive Ultrathin Film Derived from Bio-Based Urushiol-Ti by Layer-by-Layer Self-Assembly. Chem. Eng. J. 2014, 245, 265-275.

${ }^{30}$ Kim, B. H.; Lee, D. H.; Kim, J. Y.; Shin, D. O.; Jeong, H. Y. Mussel-Inspired Block Copolymer Lithography for Low Surface Energy Materials of Teflon, Graphene, and Gold. Adv. Mater. 2011, 23, 5618-5622.

${ }^{31}$ Jiang, J.; Zhu, L.; Zhu, L.; Zhang, H.; Zhu, B.; Xu, Y.; Antifouling and Antimicrobial Polymer Membranes Based on Bioinspired Polydopamine and Strong Hydrogen-Bonded Poly(N-vinyl pyrrolidone). ACS Appl. Mater. Interfaces 2013, 5, 12895-12904.

${ }^{32}$ Cho, J. H; Shanmuganathan, K.; Ellison, J. Bioinspired Catecholic Copolymers for Antifouling Surface Coatings. ACS Appl.. Mater. Interfaces 2013, 5, 3794.

${ }^{33}$ Zhang, X.; Liu, M.; Zhang, Y.; Yang, B.; Ji, Y.; Feng, L.; Tao, L.; Lia, S.; Wei Y. Combining Mussel-Inspired Chemistry and the Michael Addition Reaction to Disperse Carbon Nanotubes. RSC Adv. 2012, 2, 12153-12155.

${ }^{34}$ Chen, S.; Cao, Y.; Feng J. Polydopamine as an Efficient and Robust Platform to Functionalize Carbon Fiber for High-Performance Polymer Composites. ACS Appl. Mater. Interfaces 2014, 6, 349-356. 
${ }^{35}$ Zhu, Q.; Pan Q. Mussel-Inspired Direct Immobilization of Nanoparticles and Application for Oil/Water Separation. ACSNano 2014, 8, 1402-1409.

${ }^{36}$ Cao, Y.; Zhang, X.; Tao, L.; Li, K.; Xue, Z.; Feng, L.; Wei Y. Mussel-Inspired Chemistry and Michael Addition Reaction for Efficient Oil/Water Separation ACS Appl. Mater. Interfaces 2013, $5,4438-4442$.

37 Liu, Q.; Huanq, B.; Huanq, A. Polydopamine-Based Superhydrophobic Membranes for Biofuel Recovery. J. Mater. Chem. A 2013, 1,11970-11974.

${ }^{38}$ Neto, A. I.; Meredith, H. J.; Jenkins, C. L.; Wilker, J. J.; Mano, J. F. Combining Biomimetic Principles from the Lotus Leaf and Mussel Adhesive: Polystyrene Films with Superhydrophobic and Adhesive Layers. RSC Adv. 2013,3, 9352-9356.

${ }^{39}$ Ma, W.; Xu, H.; Takahara, A. Substrate-Independent Underwater Superoleophobic Surfaces Inspired by Fish-Skin and Mussel-Adhesives, Adv. Mat. Interfaces 2014, DOI: 10.1002/admi.201300092.

40 Zhang, L; Wu, J.; Wang, Y.; Long, Y.; Zhao, N.; Xu, J. Combination of Bioinspiration: A General Route to Superhydrophobic Particles. J. Am. Chem. Soc. 2012, 134, 9879-9881.

${ }^{41}$ Saiz-Poseu, J.; Sedó, J.; García, B.; Benaiges, C.; Parella, T.; Alibés, R.; Hernando, J.; Busqué, F.; Ruiz-Molina, D. Versatile Nanostructured Materials via Direct Reaction of Functionalized Catechols. Adv. Mater. 2013, 25, 2066-2070.

42 Lang, M.; Stelich, W. An Effective Method for the Synthesis of ${ }^{13}$ C-Labeled Polyprenylhydroxybenzoic Acids. Synthesis 2005, 6, 1019-1027.

${ }^{43}$ Saiz-Poseu, J.; Faraudo, J.; Figueras, A.; Alibés, R.; Busqué, F.; Ruiz-Molina, D. Switchable Self-Assembly of a Bioinspired Alkyl Catechol at a Solid/Liquid Interface: Competitive Interfacial, Noncovalent, and Solvent Interactions. Chem. Eur. J. 2012, 18, 3056-3063.

${ }^{44}$ Saiz-Poseu, J.; Alcón, I.; Alibés, R.; Busqué, F.; Faraudo, J.; Ruiz-Molina, D. Self-Assembly of Alkylcatechols on HOPG Investigated by Scanning Tunneling Microscopy and Molecular Dynamics Simulations. CrystEngComm 2012, 14, 264-271.

45 Watt, A. A. R.; Bothma, J. P.; Meredith, P. The Supramolecular Structure of Melanin. Soft Matter 2009, 5, 3754-3760. 
${ }^{46}$ Bersmann, F.; Ponche, A.; Ringwald, C.; Hemmerlé, J.; Raya, J.; Bechinger, B.; Voegel, J. C.; Schaaf, P.; Ball, V. Characterization of Dopamine-Melanin Growth on Silicon Oxide. J. Phys. Chem. C 2009, 113, 8234-8242.

${ }^{47}$ Dreyer, D. R.; Miller, D. J.; Freeman, B. D.; Paul, D. R.; Bielawski, C. W. Elucidating the Structure of Poly(dopamine). Langmuir 2012, 28, 6428-6435.

${ }^{48}$ Wenzel, R. N. Resistance of Solid Surfaces to Wetting by Water. Ind. Eng. Chem. 1936, 28, 988-994.

49 The net percentual oil absorption capacity is calculated as $c=100 \cdot\left(\mathrm{m}-\mathrm{m}_{0}\right) / \mathrm{m}_{0}$, where $\mathrm{m}_{0}$ and $\mathrm{m}$ represent, respectively, the dry and wet-after-draining weights of the absorbent material. Therefore, $c$ indicates the relative mass increase arising from oil absorption by the tested samples.

50 Buchholz, F.L.; Peppas, N.A. Superabsorbent Polymers; ACS Symposium Series 573; American Chemical Society: Washington, DC, 1994. 